\title{
Features of Creativity of Employees of Project Organizations with Different Types of Thinking
}

\author{
Alla Belousova ${ }^{1, *}$, Galina Kozhukhar ${ }^{2}$, and Olga Efremova $^{3}$ \\ ${ }^{1}$ Don State Technical University, Gagarin sq, 1, 344003 Rostov- on-Don, Russia \\ ${ }^{2}$ Moscow State University of Psychology and Education, Sretenka st,29, 127051 Moscow, Russia \\ ${ }^{3}$ Taganrog Institute of A.P. Chekhov (Branch) of Rostov State University of Economics, 347936 \\ Taganrog, Russia
}

\begin{abstract}
The article discusses the features of creativity and personal traits of employees of design organizations. Project activities are understood as project implementation activities in which the main components are the project team and the project. The following methods were used: Mednik's test "Diagnostics of verbal creativity" (adapted by A. N. Voronin), a questionnaire for determining the types of thinking and the level of creativity according to the method of J. Bruner, and a 16-factor questionnaire by R. Cattell. The study involved 125 employees of project consulting organizations. The results describe the relationship between different personal factors and verbal creativity in employees with different types of thinking. The reliability of the data is confirmed by the use of a set of methods of mathematical statistics.
\end{abstract}

\section{Introduction}

Project activity as a form of labor organization belongs to the field of interdisciplinary research [1-2]. Project activity is interpreted, on the one hand, as a strategy and form of company management, on the other hand, as a process of project implementation [3]. In the literature [4], the following distinctive features of project activity are distinguished: time constraints (temporary activities); a large number of risks (including critical ones); a large number of changes (including significant ones); a team is formed for a single project (as a rule).

The main categories of project activity management theory are: project and project team [1-5], which exist in conditions of sustainable development [6]. The project is considered as a process to achieve a set of interrelated goals, it is a temporary enterprise to create unique products, services or results, which is often carried out in conditions of risks of different nature [3]. The structure of project activities includes as a mandatory element the formation of a team of qualified employees to solve a complex task at a certain level of quality within the established deadlines and estimates [1,3-5]. The problems of team work in the project are studied from different positions: the features of training team project activities [5]; the study of the psychological content of the functions of participants in the organization of collaborative thinking of the project team [7]; the study of the features of decision-making, risks

\footnotetext{
*Corresponding author: belousovaak@gmail.com
} 
and the ratio of insight and competence of project participants [8]; the ratio of uncertainty, intuition and reflexivity [9]; the ratio of managers ' mentality and the ability to use various project management methods [10].

The specifics of project activities dictate additional requirements for the professional competencies of project participants. A.V. Kovalenko identifies the following categories of skills necessary for teamwork in a project [11]: technical skills or techniques necessary for the performance of work; team work skills and interpersonal communication skills necessary for team members (providing and receiving feedback, conflict resolution, understanding the value of differences, collegiality, training for the training of others); skills of active struggle for quality, including the ability to identify problems and implement improvements.

Project management standards [1] provide for three groups of interrelated knowledge elements, including: technical knowledge related to the content of project management; behavioral knowledge related to interpersonal relationships between individuals and groups [7-9] involved in projects; contextual knowledge related to the interaction of the project team [1213].

The group of behavioral competencies includes the following individual characteristics of employees of the project organization, which, among other things, include: initiative; selfcontrol; self-confidence; creativity; result orientation; productivity; focus on joint activities; sociability and openness; ability to resolve conflicts and crises; reliability; understanding of values; ethics $[1,6]$.

Thus, the analysis of the requirements for the psychological aspects of the project activity competencies of its participants shows that with different approaches [14], researchers assume the development of the success of project activity depending on the development of creativity, thinking and personal qualities [7-9, 15] participants as necessary elements of the organization of successful project activities.

In this regard, we believe that, as it has been shown in the literature [7, 14-15] personal qualities of employees of project organizations act as factors that allow to improve the project activities of employees, to initiate their creativity and thinking, contributing to the successful solution of the tasks and goals facing the project team. But if you do not develop the thinking and creativity of employees, you can hardly expect effective project activities in the structure of professional activity, since an important source of innovation is the creativity and resources of human thinking [7-9, 11, 15].

This article is devoted to the study of the relationship of personal qualities and creativity employees of project organizations with different types of thinking that allow you to predict the level of success of project activities. Project activity is one of the components that largely ensure the adoption and implementation of innovations in various spheres of life related to the production and promotion of projects [14]. We believe that employees who carry out professional activities through the implementation of various projects develop personal qualities that contribute to the initiation of various types of thinking and creativity.

\section{Materials and Methods}

The main purpose of the study is to study the relationship between the characteristics of personal qualities and creativity of employees of project organizations with different types of thinking.

The following methods of psychodiagnostics were used:

1. For the study of the type of thinking, the questionnaire was used by J. Bruner, which is aimed at studying the individual profile of thinking and the level of creativity. The method allows us to identify four main types, including: objective, figurative, sign and symbolic thinking, and to determine creativity [16]. Creativity is a characteristic of the profile and the degree of development of the ability to think creatively, to find non-standard solutions to the 
problem. The obtained values of creativity belong to three levels: high (from 10 to 15 points); medium (from 6 to 9 points); low (from 0 to 5 points) [16].

2. The definition of verbal creativity was made using the test of distant associations of $\mathrm{S}$. Mednik, in the adaptation of A. N. Voronin [17]. The test is designed to diagnose creativity, which is defined as the thought process of forming associations into new combinations that would meet certain semantic and semantic requirements. The more the elements of the new combination are removed from each other, the higher the creativity. The method is aimed at identifying and evaluating the existing creative potential of the individual, often blocked or hidden, which is expressed in the originality of the speech-thinking activity of the individual [17].

3. To identify the individual psychological characteristics of the subjects ' personality, the R. Cattell test, variant A, was used. The methodology contains 187 questions, which are given 3 possible answers. As a result of the study, the personality is described by 16 fundamentally independent and psychologically meaningful factors. Each factor has a conditional name and assumes a stable probabilistic relationship between individual personality traits [18].

Sample: the study was conducted on the basis of the city of Rostov-On-Don. The study involved 125 people-employees of project consulting organizations (61 women and 64 men), including 31 employees of research organizations (16 women and $15 \mathrm{men}$ ), 48 people engaged in project activities in the field of IT consulting (15 women and 33 men), 46 people involved in projects in other areas (30 women and 16 men).

For statistical data processing, the program SPSS. v. 23 (descriptive statistics, correlation analysis) was used.

\section{Results}

In accordance with the objectives of our study, we analyzed the thinking profiles across the entire sample and examined each profile separately. The type of thinking was determined using the "Profile of Thinking" technique, which identifies 4 basic types: objective, figurative, sign and symbolic. The prevailing type of thinking is determined by the maximum value of points on the corresponding scales. The respondents who scored the same maximum number of points for several types of thinking were assigned to the mixed type (Table 1).

According to the results obtained, in the sample of employees of project organizations, the predominant type of thinking is the sign $40.8 \%$. The least represented objective type of thinking is $6.4 \%$. The other types are more evenly represented - symbolic $21.6 \%$, figurative $16 \%$ and mixed $15.2 \%$.

The low percentage of the representation of the objective type of thinking is probably due to the peculiarities of the sample, whose representatives are engaged in project activities in the field of consulting, research and programming, which are characterized more by abstract types of thinking, in which information is transformed using symbols and inferences, than with physical objects.

Table 1. Descriptive statistics of the representation of types of thinking

\begin{tabular}{|l|c|c|c|c|}
\hline Thinking type & Frequency & Percentage & Valid\% & $\begin{array}{c}\text { Cumula- } \\
\text { tive\% }\end{array}$ \\
\hline Objective & 8 & 6.4 & 6.4 & 6.4 \\
\hline Symbolic & 27 & 21.6 & 21.6 & 28.0 \\
\hline Sign & 51 & 40.8 & 40.8 & 68.8 \\
\hline Figurative & 20 & 16.0 & 16.0 & 84.8 \\
\hline Mixed & 19 & 15.2 & 15.2 & 100.0 \\
\hline
\end{tabular}




\begin{tabular}{|l|c|c|c|c|}
\hline Total & 125 & 100 & 100 & \\
\hline
\end{tabular}

For employees of project organizations who participated in the study, the distribution by level of creativity is presented as follows (Table 2): 6.4\% (8) of respondents with a low level of creativity, 59.2\% (74) with an average level and 34.4\%(43) with a high level.

Table 2. Descriptive statistics of the representation of creativity

\begin{tabular}{|l|c|c|c|c|}
\hline The level of creativity & Frequency & Percentage & Valid\% & $\begin{array}{c}\text { Cumula- } \\
\text { tive\% } \%\end{array}$ \\
\hline Low level & 8 & 6.4 & 6.4 & 6.4 \\
\hline Average level & 74 & 59.2 & 59.2 & 65.6 \\
\hline High level & 43 & 34.4 & 34.4 & 100.0 \\
\hline Total & 125 & 100 & 100 & \\
\hline
\end{tabular}

For verbal creativity, it was found that the employees of the project organizations who participated in the study had creativity above the limits of the average level (Table 3).

Table 3. Descriptive statistics of the representation of verbal creativity

\begin{tabular}{|l|c|c|c|c|}
\hline The level of creativity & Frequency & Percentage & Valid\% & $\begin{array}{c}\text { Cumula- } \\
\text { tive\% }\end{array}$ \\
\hline $0 \%$ & 13 & 10.4 & 10.4 & 10.4 \\
\hline $20 \%$ & 10 & 8.0 & 8.0 & 18.4 \\
\hline $40 \%$ & 23 & 18.4 & 18.4 & 36.8 \\
\hline $60 \%$ & 27 & 21.6 & 21.6 & 58.4 \\
\hline $80 \%$ & 52 & 41.6 & 41.6 & 100.0 \\
\hline Total & 125 & 100 & 100 & \\
\hline
\end{tabular}

The analysis using the Cruskall-Wallis test confirmed the presence of significant differences in creativity and verbal creativity for groups with different types of thinking (Table 4).

Table 4. Significance of differences in creativity and verbal creativity according to the Kruskal-Wallace criterion for groups with different types of thinking

\begin{tabular}{|l|l|l|l|l|}
\hline & The null hypothesis & \multicolumn{1}{|c|}{ The Criterion } & $\begin{array}{l}\text { The Signif- } \\
\text { icance }\end{array}$ & The Solution \\
\hline 1 & $\begin{array}{l}\text { The distribution of Ver- } \\
\text { bal creativity is the same } \\
\text { for the categories of Type } \\
\text { of thinking }\end{array}$ & $\begin{array}{l}\text { Kruskal-Wallis cri- } \\
\text { terion for independ- } \\
\text { ent samples }\end{array}$ & 0,002 & $\begin{array}{l}\text { The null hypoth- } \\
\text { esis is rejected }\end{array}$ \\
\hline 2 & $\begin{array}{l}\text { The distribution of Crea- } \\
\text { tivity is the same for the } \\
\text { categories of Type of } \\
\text { thinking }\end{array}$ & $\begin{array}{l}\text { Kruskal-Wallis cri- } \\
\text { terion for independ- } \\
\text { ent samples }\end{array}$ & 0,000 & $\begin{array}{l}\text { The null hypoth- } \\
\text { esis is rejected }\end{array}$ \\
\hline
\end{tabular}

Next, we will consider the most important correlations in the context of this work at the significance level of $\mathrm{p} \leq 0.01(* *)$ and $\mathrm{p} \leq 0.05(*)$.

For the Objective type of thinking, no significant correlation was found between creativity and verbal creativity. Creativity is associated with the factor O, i.e., with a tendency to self-doubt, anxiety in difficult situations $(\mathrm{O}, \mathrm{r}=0.756$ at $\mathrm{p} \leq 0.05)$.

Verbal creativity has inversely proportional relationships with the following personality factors: practicality, rationality and logic $(\mathrm{I}, \mathrm{r}=-0.748$ at $\mathrm{p} \leq 0.05)$, group orientation and collective decisions $(\mathrm{Q} 2, \mathrm{r}=-0.889$ at $\mathrm{p} \leq 0.01)$, high sensitivity, attention to detail, slow decision-making $(\mathrm{F} 3, \mathrm{r}=-0.756$ at $\mathrm{p} \leq 0.05)$. Therefore, we can say that the higher the verbal 
creativity of employees with objective thinking, the lower their practicality and rationality, the lower their focus on the group and collective decisions, the less they pay attention to details.

For the objective type of thinking, creativity was associated with the factor of the group of emotional properties, for verbal creativity, the factor from the group of communicative properties was also significant. The results obtained are probably explained by the fact that the object type of thinking is characterized by the perception and transformation of information in close relationship with objects of the real world, which imposes certain restrictions associated with the complexity of going beyond the knowledge of existing objects. Nevertheless, such qualities as anxiety in difficult situations and self-doubt will force a person to check their decision, to look for all new options, which in turn can allow you to detect a nonstandard move. Also, the focus on the group in the structure of creativity seems to us to be the specifics of the project sphere of activity, since in joint activities such qualities as the ability to negotiate, the desire to find an option suitable for each participant are among the main personal competencies.

The connection of verbal creativity with rationality and logic can be interpreted by the desire to explain, to get to the bottom of it, while remaining only in the practical plane, which allows you to see solutions that lie beyond the usual and more obvious ones. The focus on the group and the desire for a collective decision, agreement, make a person take into account a whole range of different aspects, dependence on the admiration of the group in the extreme, also encourages the development of unique results.

For the Symbolic type of thinking, a correlation was found between creativity and verbal creativity $(\mathrm{r}=0.508$ at $\mathrm{p} \leq 0.01)$ and relationships with personality traits were revealed.

Creativity is positively associated with the following traits: assertiveness, willingness to defend interests, tendency to dominance $(\mathrm{E}, \mathrm{r}=0.448$ at $\mathrm{p} \leq 0.05)$, expressiveness, energy, tendency to inattention $(\mathrm{F}, \mathrm{r}=0.402$ at $\mathrm{p} \leq 0.05)$, autonomy, independence and independence in social behavior $(\mathrm{L}, \mathrm{r}=0.509$ at $\mathrm{p} \leq 0.01)$, ability to establish and maintain social contacts $(\mathrm{F} 2, \mathrm{r}=0.509$ at $\mathrm{p} \leq 0.01)$, free thinking, tendency to experiments, innovation $(\mathrm{Q} 1, \mathrm{r}=0.520$ at $\mathrm{p} \leq 0.01$ ), propensity to solve practical problems, orientation to external reality $(\mathrm{M}, \mathrm{r}=$ 0.448 at $\mathrm{p} \leq 0.05$ ). There are also inversely proportional relationships: straightforwardness, frankness and naturalness $(\mathrm{N}, \mathrm{r}=-0.517$ at $\mathrm{p} \leq 0.01)$, a tendency to high anxiety, a tendency to dissatisfaction with what has been achieved $(\mathrm{F} 1, \mathrm{r}=-0.477$ at $\mathrm{p} \leq 0.05)$, practicality, rationality and logic $(\mathrm{I}, \mathrm{r}=-0.402$ at $\mathrm{p} \leq 0.05)$.

The identified relationships relate to the features of the emotional, communicative and intellectual groups of properties. Among the intellectual traits, there is a focus on practice and a propensity for innovation, freedom of thought. For people with this type of thinking, creativity is determined not by focusing on the group and its interests (as for objective, figurative types of thinking), but on the contrary, by a greater focus on oneself, which is probably due to the peculiarities of the thought process, when the degree of abstraction of thinking is higher and analytical inclinations are developed to a greater extent than orientation to external, physical objects.

Verbal creativity is positively associated with personality factors: abstract thinking, efficiency, rapid learning, overall high level of mental abilities $(B, r=0.575$ at $p \leq 0.01)$, assertiveness, willingness to defend interests, tendency to dominance $(\mathrm{E}, \mathrm{r}=0.507$ at $\mathrm{p} \leq 0.01)$, balance, perseverance in achieving goals, accuracy, business orientation $(\mathrm{G}, \mathrm{r}=0.404$ at $\mathrm{p} \leq$ $0.05)$, autonomy, independence and independence in social behavior $(\mathrm{L}, \mathrm{r}=0.664$ at $\mathrm{p} \leq$ $0.01)$, freedom of thought, tendency to experiment, innovation $(\mathrm{Q} 1, \mathrm{r}=0.541$ at $\mathrm{p} \leq 0.01)$, the ability to establish and maintain social contacts $(\mathrm{F} 2, \mathrm{r}=0.531$ at $\mathrm{p} \leq 0.01)$. Also, verbal creativity has negative associations with the following personality factors: a tendency to high anxiety, a tendency to dissatisfaction with what has been achieved ( $F 1, r=-0.502$ at $\mathrm{p} \leq 0.01)$, high sensitivity, attention to detail, slow decision-making $(F 3, r=-0.397$ at $\mathrm{p} \leq 0.05)$. 
Verbal creativity for individuals with a symbolic type of thinking is associated with intellectual, communicative, and regulatory groups of traits. It can be assumed that the regulatory component, expressed in perseverance in achieving the goal, business orientation, is associated with creativity, as a factor that supports cognitive activity in situations of complex problems characteristic of project activities.

In total, there were 9 correlations between creativity and personal factors, and 8 correlations between verbal creativity and personal factors, which seems to indicate a strong connection between these phenomena.

For the Sign type of thinking, a correlation was found between creativity and verbal creativity $(\mathrm{r}=0.508$ at $\mathrm{p} \leq 0.01)$ and relationships with personality traits were revealed.

Creativity is associated with the following traits: expressiveness, energy, a tendency to inattention $(\mathrm{F}, \mathrm{r}=0.291$ at $\mathrm{p} \leq 0.05)$, free thinking, a tendency to experiment, innovation $(\mathrm{Q} 1$, $\mathrm{r}=0.294$ at $\mathrm{p} \leq 0.05)$, group orientation and collective decisions $(\mathrm{Q} 2, \mathrm{r}=-0.287$ at $\mathrm{p} \leq 0.05)$.

Verbal creativity is positively associated with the following factors: activity, courage, readiness to join new groups $(\mathrm{H}, \mathrm{r}=0.344$ at $\mathrm{p} \leq 0.05)$, freedom of thought, tendency to experiment, innovation ( $\mathrm{Q} 1, \mathrm{r}=0.388$ at $\mathrm{p} \leq 0.01$ ), ability to establish and maintain social contacts $(\mathrm{F} 2, \mathrm{r}=0.296$ at $\mathrm{p} \leq 0.05)$. Verbal creativity also has negative associations with the following personality factors: high sensitivity, attention to detail, slow decision-making (F3, $\mathrm{r}=-0.733$ at $\mathrm{p} \leq 0.01)$, impulsivity, lack of agreement with generally accepted moral rules and standards $(\mathrm{G}, \mathrm{r}=-0.307$ at $\mathrm{p} \leq 0.05)$, group orientation and group support $(\mathrm{F} 4, \mathrm{r}=-0.529$ at $\mathrm{p} \leq 0.01)$.

The identified traits belong to the groups of intellectual, emotional, volitional and communicative personality traits. The factor of receptivity to new things, freedom of thought, was associated with both creativity, measured by the method of professional thinking, and verbal creativity. The results suggest that for an employee with a symbolic type of thinking engaged in project activities, creativity is explained by expressiveness, the ability to overcome existing barriers, the desire to experiment and be active, while focusing on group interests.

For the Figurative type of thinking, no significant correlation was found between creativity and verbal creativity, and relationships with various personality traits were revealed.

Creativity is associated with the following personality traits: positive relationships with factors - activity, courage, readiness to join new groups $(\mathrm{H}, \mathrm{r}=0.614$ at $\mathrm{p} \leq 0.01)$, propensity to solve practical problems, orientation to external reality $(\mathrm{M}, \mathrm{r}=0.784$ at $\mathrm{p} \leq 0.01)$, independence, orientation to one's own solutions ( $Q 2, r=0.487$ at $\mathrm{p} \leq 0.05)$; negative relationships were found with the factor - concreteness, difficulty in solving abstract problems $(\mathrm{B}, \mathrm{r}$ $=-0.463$ at $\mathrm{p} \leq 0.05)$,

Verbal creativity has negative correlations with personal factors: high sensitivity, attention to detail, slow decision-making $(\mathrm{F} 3, \mathrm{r}=-0.466$ at $\mathrm{p} \leq 0.05)$, group orientation and group support $(\mathrm{F} 4, \mathrm{r}=-0.460$ at $\mathrm{p} \leq 0.05)$.

The traits that determine creativity for employees with an imaginative type of thinking lie in the groups of intellectual, communicative and emotional properties. Of interest is the negative relationship between creativity and intelligence, since it is known that creativity, up to a certain threshold, is associated with high intellectual performance. This result can probably be explained precisely by the influence of the role of the imaginative thinking of the employee of the project organization, as a way of perceiving information that is more coherent with the objectivity and orientation to the practical tasks of external reality.

For the Mixed type of thinking, no significant correlation was found between creativity and verbal creativity, and relationships with various personality traits were revealed.

Creativity is associated with the following personality traits: positive relationships with factors-emotional sensitivity $(\mathrm{I}, \mathrm{r}=0.500$ at $\mathrm{p} \leq 0.05)$, propensity to solve practical problems, 
orientation to external reality $(\mathrm{M}, \mathrm{r}=0.747$ at $\mathrm{p} \leq 0.01)$, free thinking, propensity to experiment, innovation $(\mathrm{Q} 1, \mathrm{r}=0.574$ at $\mathrm{p} \leq 0.05)$, expressiveness, energy, tendency to inattention $(\mathrm{F}, \mathrm{r}=0.656$ at $\mathrm{p} \leq 0.01)$; negative associations were found with the factor-impulsivity, lack of agreement with generally accepted moral rules and standards $(\mathrm{G}, \mathrm{r}=-0.615$ at $\mathrm{p} \leq 0.01)$, restraint in the expression of feelings, focus on accuracy and attention to detail ( $F 2, r=-0.505$ at $\mathrm{p} \leq 0.05)$.

Personal characteristics are represented by the spheres of communicative, intellectual and emotional properties. For a mixed type of thinking, it is characteristic that the subject uses equally well different ways of perceiving, analyzing and processing information, which explains its wide range of qualities involved in the creative process.

Verbal creativity is related to: propensity to solve practical problems, orientation to external reality $(\mathrm{M}, \mathrm{r}=0.549$ at $\mathrm{p} \leq 0.05)$, orientation to the group and group support $(\mathrm{F} 4, \mathrm{r}=-$ 0.614 at $\mathrm{p} \leq 0.01$ ). Explaining the relationship, we can refer to the position that the structural features of creativity may depend on the specification of the activity. In the project form of the work, the high importance of the practical orientation is traced, since the project is intended primarily for the implementation of the tasks of applied activity.

\section{Discussion}

We have empirically confirmed the hypothesis of differences in creativity in relation to personal factors for employees with different types of thinking: we have not identified a single trait that would be associated with each of the types of thinking. The set of personal factors for each type of thinking is unique, which, apparently, allows us to speak about the uniqueness of the manifestations of creativity for people with different types of thinking. Similar conclusions can be found in $[14,19]$.

For the subject and sign types of thinking, personal traits associated with creativity are revealed, expressed in group orientation (negative relationship with the Q2 factor), while for the figurative and symbolic types, creativity is associated with the opposite trend - self-orientation (positive relationship with the Q2 factor).

For the object type and symbolic type, creativity is associated with practicality, rationality, and logic (a negative relationship with factor I), while for mixed thinking, the inverse relationship of creativity with this factor is found. For the mixed type of thinking creativity is interrelated with the emotional sensitivity.

Opposite relationships in factor B were found for creativity in individuals with the types of thinking figurative and symbolic. Thus, for the symbolic type, creativity is associated with a high learning rate, abstract thinking, and for the figurative type of thinking, creativity is associated with less developed these characteristics.

For people with a symbolic mindset, creativity is related to the $\mathrm{G}$ factor, and for people with a symbolic mindset and a mixed mindset, the relationship is reversed. Thus, in symbolic thinking, creativity is promoted by balance, perseverance in achieving goals, accuracy, business orientation, for a mixed type and a sign - it is promoted by impulsivity, lack of agreement with generally accepted moral rules and standards.

Anxiety (factor O) was associated with creativity, only for persons with the subject type; autonomy, independence and independence in social behavior (factor L), straightforwardness (factor N) - only for persons with a symbolic type of thinking.

Traits that clearly contribute to creativity for individuals with those types of thinking in which these traits have developed into a personal structure: activity, courage, willingness to join new groups (factor $\mathrm{H}$ ), assertiveness, willingness to defend interests, tendency to dominance (factor E) expressiveness, energy, tendency to inattention (factor F), tendency to solve practical problems, orientation to external reality (factor $M$ ), free thinking, tendency to experiment, innovation $(\mathrm{Q} 1)$. 
Based on the analysis of the relations of creativity with personal characteristics in individuals with different types of thinking, it can be assumed that there is a tendency to complicate the structure of relations depending on the way the subject represents the world: the less pronounced the connection of thinking processes with real objects, the more multilevel the determination of the structure of creativity. However, further study of the described connection is a perspective of our work and requires further study and reflection.

\section{Conclusions}

In the course of conducting an empirical study of the features of creativity for employees with different types of thinking in project organizations, the results were obtained that reveal the sets of personality traits that contribute to creativity for people with different types of thinking.

For the subject type of thinking, the features of factors I (Harria), O (Hypothymia), Q2 (Sociability) are characteristic);

for the figurative type of thinking - B (Low intelligence), H (Parmia), M (Autism), Q2 (Self-sufficiency);

for the sign type of thinking - F (Surgensy), G (Weakness of the "Superego"), H (Parmia), Q1 (Radicalism), Q2 (Sociability);

for the symbolic type of thinking - B (High intelligence), E (Dominance), I (Harria), F (Surgency), G (Super-Ego Power), L(Protension), M (Autism), N (Straightforwardness ), Q1 (Radicalism);

for a mixed type of thinking - F (Surgensia ), G (Weakness of the "Superego"), I (Premsia), M (Autism), Q1 (Radicalism)..

\section{References}

1. Project Management Institute Inc. A Guide to the Project Management Body of Knowledge (PMBOK guide, 2017).

2. D. Muslihat, 7 Popular Project Management Methodologies And What They're Best Suited For (2018). https://zenkit.com/en/blog/7-popular-projectmanagementmethodologies-and-what-theyre-best-suited-for/ (Last accessed 2021/03/05)

3. J. Heagney, Fundamentals of project management. 5th Edition. American management association (New-York, 2016)

4. E. Kirchler, Economic psychology. Cambridge University Press (Cambridge, 2018)

5. H.M. Gharaibeh, Project team learning in mega projects: are we truly learning the lessons? International Journal of Project Organisation and Management 8(1), 87-102 (2016)

6. R. Roberto Farias de Toledo, H.L. Miranda Junior, J.R. Farias Filho, H. Gomes Costa, A scientometric review of global research on sustainability and project management dataset (2019).

7. A. Belousova, Functions of Participants in the Collaborative Solution of Thinking Problems. International Journal of Cognitive Research in Science, Engineering and Education-IJCRSEE 8 (SI), 29-36 (2020)

8. B.J. Galli, M. Amin Kaviani, L.A. Ocampo, Relationships of economic decision-making and risk in the project environment: insights from the literature. International Journal of Project Organization and Management 11(2), 110-139 (2019) 
9. D.P. Velayudhan, S. Thomas, Role of technological uncertainty, technical complexity, intuition and reflexivity in project planning - a study on software development projects. International Journal of Project Organization and Management 10(1), 82-92 (2018)

10. V. Pishchik, A. Belousova, Y. Rashchupkina, A. Shorokhov, Methodology of project management and type of economic mentality of managers of $\mathrm{x}$ and $\mathrm{y}$ generations. E3S Web of Conferences 175 (2020)

11. N.A. Ziroyan, Building an effective team in an organization (on the example of PJSC Sberbank of Russia). Actual problems of aviation and cosmonautics, 13, (2017). https://cyberleninka.ru/article/n/postroenie-effektivnoy-komandy-v-organizatsii-naprimere-pao-sberbank-rossii (Last accessed 2021/03/15)

12. A. Belousova, G. Kozhukhar, M. Vyshkvyrkina, V. Ermak, The role of perceptual attitudes of managers in the cognition of employees of the organization. E3S Web of Conferences 210 (2020)

13. E. Suroedova, Y. Tushnova, E. Belousova, Agriculture faculty students' meanings translation in conditions of the development of communicative competence. E3S Web of Conferences 175 (2020)

14. I. Abdullah, R. Omar, S. Aisyha Panatik, A Literature Review on Personality, Creativity and Innovative Behavior. International Review of Management and Marketing 6(1), 177-182 (2016)

15. R. M. Belbin, Team Roles at Work. Routledge (London, 2012)

16. G.S. Nikiforov, Management psychology. Psychological workshop (Moscow, Prospect, 2021)

17. V.N. Druzhinin, Psychology of general abilities. (Yurayt Publishing House, Moscow (2019).

18. D.Ya. Raigorodsky, Practical psychodiagnostics: techniques and tests (Bakhrakh, Samara, 2011)

19. T.M. Amabile, J. Pillemer, Perspectives on the Social Psychology of Creativity, Journal of Creative Behavior, 46(1), 3-15 (2012) doi: 10.1002 / jocb.001 